\title{
Diet, genetic susceptibility and carcinogenesis
}

\author{
Paolo Vineis* \\ Unit of Cancer Epidemiology, University of Torino and CPO-Piemonte, via Santena 710126 Torino, Italy
}

\begin{abstract}
At least six types of gene-environment interactions (GEI) have been proposed (Kouhry and Wagener, 1993). In the first type, neither the environmental exposure (EE) nor the genetic risk factor (GRF) have any effect by themselves, but interaction between them causes disease. This is the case of phenylalanine exposure and the phenylketonuria genotype. Type 2 is a situation in which the GRF has no effect on disease in the absence of exposure, but exacerbates the effects of the latter. This is the most important type of GEI in relation to metabolic susceptibility genes and human carcinogenesis. The third type is the converse of the second (EE is ineffective per se, but enhances the effect of GRF). Type 4 occurs when both EE and GRF increase the risk for disease, but the combination is interactive or synergistic: an example is the interaction between Xeroderma Pigmentosum and UV radiation. Types 5 and 6, according to the classification proposed by Kouhry, refer to cases in which the GRF is protective.

The model of GEI that is emerging as the most important in chemical carcinogenesis refers to metabolic susceptibility genes. The general population can be divided into subgroups depending on their susceptibility to the action of carcinogens, based on their ability to metabolize such compounds to electrophilic, reactive metabolites (which form adducts with DNA), or, respectively, electrophobic metabolites that are excreted. The present contribution is a short review of the relevant literature, with particular emphasis on some polymorphisms involved in dietary exposures. In addition, the practical implications of genetic testing in this field are discussed.
\end{abstract}

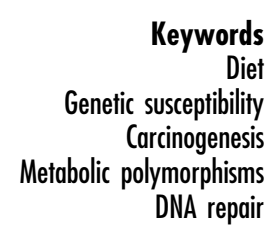

\section{Cancer genes}

It is becoming clear that single highly-penetrant mutations in 'cancer genes' explain a very small proportion of cancers $^{1}$ (penetrance is the strength of the association between a mutation and the risk of disease, expressed by the proportion of the mutation carriers who develop the phenotypic manifestations). This consideration arises both from empirical observation and from general scientific knowledge. Highly-penetrant gene mutations that confer an exceptionally high risk of cancer in the carriers - represent the tail of a distribution that includes: (a) more common mutations in the same cancer genes (polymorphisms), that have a less disruptive effect on the protein function; or (b) rare or common mutations in genes that are less directly involved in the cancer process. There is increasing evidence that both categories may play a role in carcinogenesis. Mohrenweiser and colleagues ${ }^{2}$ have shown that even genes involved in rare and disruptive conditions such as Xeroderma Pigmentosum show common polymorphisms whose effects on the protein function (a DNA repair enzyme) are probably mild.

Concerning category (b), many metabolic polymorphisms are a clear example. Subjects with the GSTM1 'null' genotype are frequent (about 50\% of the population), have a serious genetic change (a deletion of the entire gene), but a slightly increased risk for some forms of cancer. Rare and highly-penetrant mutations in 'cancer genes' may act without interacting with external exposures; this is not necessarily the rule, since XP is itself one of the best examples of geneenvironment interaction, and there is evidence that dietary factors may have a greater impact in women with one or more first degree relatives with breast cancer than in women without familiarity ${ }^{3}$. However, gene-environment interactions are the rule in the case of low-penetrance genes.

There are not many examples of interaction between genetic susceptibility, dietary exposures and the risk of cancer. I will review two prominent examples in the following. 


\section{Metabolic polymorphisms: examples of interaction between dietary components and genetic susceptibility}

\section{Metbylenetetrabydrofolate reductase polymorphism}

Common genetic polymorphisms have been reported in the gene encoding methylenetetrahydrofolate reductase (MTHFR), the enzyme that produces 5-methyltetrahydrofolate (5-methyl-THF) required for the conversion of homocysteine to methionine. In individuals with the val/ val genotype, functional effects include elevations in plasma homocysteine and differences in response to folic acid supplementation. The metabolic changes associated with such genotype have been reported to modify the risk for chronic disease (e.g., vascular disease and cancer) and neural tube defects in conjunction with folate deficiency. Folate intake requirements may be different in affected individuals relative to normal or heterozygous individuals. The complex interaction between this common genetic polymorphism of MTHFR and folate intake is the focus of intense investigation ${ }^{4}$.

In a study in the U.S. an inverse association of the val/ val polymorphism in the MTHFR gene was associate with colorectal cancer. The inverse association of methionine and adverse association of alcohol with colorectal cancer were stronger among val/val individuals. These interactions were not present in studies of colorectal adenomas $^{5,6}$. In another study, the association between the same allele of the MTHFR gene and ischemic stroke in an elderly Japanese population was examined. In 256 stroke patients and 325 control subjects, the frequencies of the allele were 0.45 and 0.32 , respectively. The odds ratios and 95\% confidence intervals adjusted for the other risk factors were, respectively, 1.51 (1.02 to 2.23) for the adenine/valine genotype and 3.35 (1.94 to 5.77) for the $\mathrm{val} / \mathrm{val}$ genotype compared with the adenine/adenine genotype ${ }^{7}$.

Moderate elevation of plasma total homocysteine (tHcy) is a strong and independent risk factor for coronary artery disease (CAD). It can result from genetic or nutrient-related disturbances in the transsulfuration or remethylation pathways for homocysteine metabolism. Studies on the role of the $\mathrm{A} / \mathrm{V}$ mutation as a risk factor for CAD have given conflicting results. In one study, a total of 415 subjects, 278 with angiographically documented multivessel CAD and 137 with angiographically documented normal coronary arteries were included. The overall frequency of the MTHFR V/V homozygous genotype was $15.7 \%$ (with $52.5 \%$ heterozygous and $31.8 \%$ normal). Subgroup analysis showed no significant differences between CAD and CAD-free subjects. However, among individuals with folate levels below the median, fasting tHcy was significantly increased not only in $\mathrm{V} / \mathrm{V}$ homozygotes (by 59\%) but also in $\mathrm{A} / \mathrm{V}$ heterozygotes (by $21 \%$ on average) ${ }^{8}$.
The polymorphism in MTHFR, plasma tHCY, and folate using baseline blood levels were examined among 293 Physicians' Health Study participants who developed myocardial infarction (MI) during up to 8 years of follow-up and 290 control subjects. Compared with those with genotype $\mathrm{A} / \mathrm{A}$, the relative risk (RR) of $\mathrm{MI}$ among those with $\mathrm{A} / \mathrm{V}$ was 1.1 (95\% CI, 0.8 to 1.5$)$, and it was 0.8 ( 0.5 to 1.4$)$ for the $\mathrm{V} / \mathrm{V}$ genotype; none of these RRs were statistically significant. However, those with genotype $\mathrm{V} / \mathrm{V}$ had an increased mean tHCY level (mean \pm SEM, $\quad 12.6 \pm 0.5 \mathrm{nmol} / \mathrm{mL}$ ), compared with those with genotype A/A $(10.6 \pm 0.3)(P<.01)$. This difference was most marked among men with low folate levels (the lowest quartile distribution of the control subjects): those with genotype $\mathrm{V} / \mathrm{V}$ had tHCY levels of $16.0 \pm 1.1 \mathrm{nmol} / \mathrm{mL}$, compared with $12.3 \pm 0.6 \mathrm{nmol} / \mathrm{mL}$ $(P<.001)$ for genotype $\mathrm{A} / \mathrm{A}$. Therefore, gene-environment interaction might increase the risk by elevating tHCY, especially when folate intake is low 9 .

\section{Colon cancer, heterocyclic aromatic amines and NAT2}

Heterocyclic aromatic amines are a group of experimental carcinogens that are formed when meat is fried. They are metabolized via pathways similar to those for other arylamines like 4-aminobiphenyl or 2-naphthylamine, i.e. $\mathrm{N}$-acetylation and $\mathrm{N}$-oxidation. $\mathrm{N}$-acetylation is performed by the polymorphic non-inducible enzyme N-acetyltransferase, under control of the genes NAT1 and NAT2; N-oxidation is performed by CYP1A2, which is an inducible enzyme of the mixed-function oxidase group.

A positive association between the 'rapid acetylator' phenotype and the risk of colon cancer has been shown in some studies but not in others (Table 1). The $\mathrm{N}$-acetyltransferase phenotypes are approximately bimodally distributed, with around $40 \%$ of persons in European populations being 'rapid acetylators'. As Table 1 shows, the slow acetylator phenotype seems to exert a rather strong protective effect (OR around 0.3-0.4), compared to the rapid acetylator phenotype, in three studies based on the phenotype. In one study measuring the phenotype and three studies based on the genotype (i.e. on the identification of mutations in the NAT2 gene), however, no association was found. A particularly interesting finding was reported from a study in Australia $^{10}$, where an association between high levels of meat consumption and colon adenoma or carcinoma was detected among rapid acetylators only (Table 1). A Japanese study looked at the relationship between the NAT2 genotype and mutations in the K-ras oncogene (Odds Ratio $=0.2$ for rapid acetylators, 95\% confidence interval 0.03-1.0). Overall, these findings can be interpreted as reflecting the greater ability of rapid acetylators to activate heterocyclic aromatic amines to carcinogenic derivatives within the colon mucosa. Although such 
Table 1 Relative risks of colon cancer according to the acetylator phenotype: slow vs. rapid acetylators ${ }^{11}$

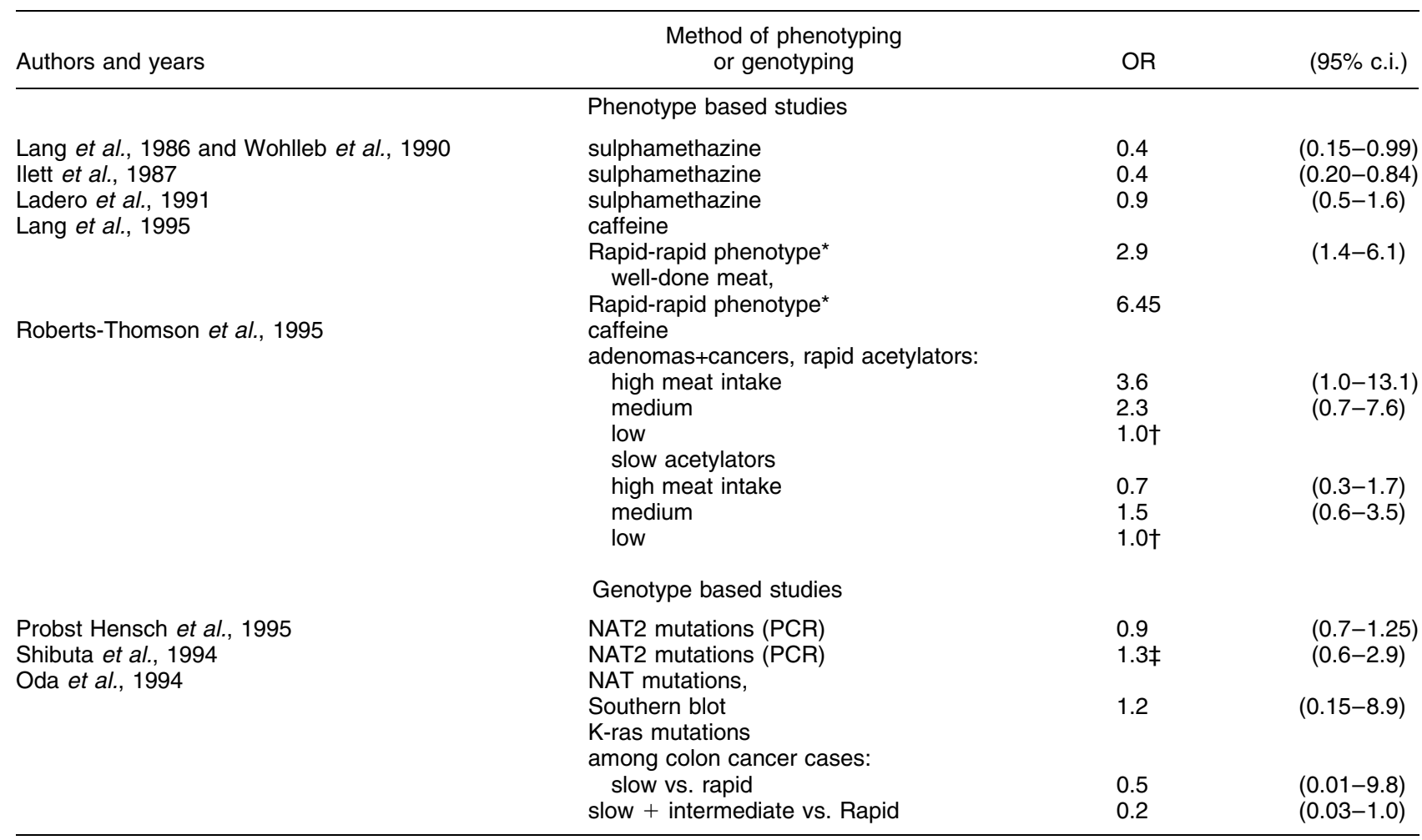

* Rapid acetylators, rapid oxidizers (CYP1A2).
† Reference category.

‡ Mantel-Haenszel estimate (age-adjusted).

interpretation is still largely speculative, mainly due to inconsistencies among phenotype-based vs. genotypebased studies, this is clearly an important field of work. Further corroborating evidence came from one study in mice showing that rapid acetylators had 3-fold more DNA adducts, formed by the food carcinogen 2-amino-3methyl-imidazo(4,5-f)quinoline (IQ) in the colon mucosa, than slow acetylators.

Inter-individual variability in metabolic susceptibility to carcinogens may be particularly important at low levels of environmental exposure. While at high-level exposure both rapid and slow metabolisers undergo saturation of the enzyme activity, this is unlikely to happen at low doses. Therefore, the risk-modulating effect of the metaboliser phenotype is likely to be more evident at low doses. For example, there is evidence of cancer risk modulation by metaboliser phenotype in relation to exposures to environmental tobacco smoke (ETS) and polycyclic aromatic hydrocarbons (such as in vehicle exhaust), each of which occurs at very low levels in the ambient environment (and affects a large proportion of the population). Likewise, low-dose exposure to heterocyclic aromatic amines is widespread: HAA are found in particular in cured and smoked meat, and in meat cooked quickly at high temperatures, usually at low doses ${ }^{11}$.

There are at least three reasons why any screening for the acetylation pattern would be inappropriate. One is scientific uncertainty that still surrounds the issue. The second is the complexity of metabolic patterns, that hampers the simplified logic of screening for one or a few traits. The third reason has already been described above: while the NAT rapid genotype is frequent, its penetrance is quite low, so that the predictive value in terms of longterm risk is too small to give any practical benefit (as opposed, for example, to screening families for highlypenetrant mutations such as those involved in familial syndromes). The latter subject will be dealt with in more detail in a following paragraph.

\section{Mutagen sensitivity}

The examples above refer to metabolic polymorphisms, i.e. to the genetically-based ability to metabolize carcinogens. In addition, many investigations ${ }^{12-44}$ have been conducted on a greater susceptibility of cancer patients to DNA damage, in comparison with controls. Most of these studies are based on the treatment of white blood cells (WBC) from cases and controls with a mutagen or a clastogen and on the observation of the frequencies of the induced DNA damage. The differences between cases and controls are interpreted as suggesting a greater susceptibility of cancer cases. The interpretation of such studies, however, is not completely straightforward. In particular, the meaning of 'mutagen sensitivity' tests is 
uncertain. Although virtually all studies show a greater 'sensitivity' of cases, one cannot rule out that the apparent sensitivity is not due to a susceptibility factor, but is a consequence of genetic instability related to cancer itself. Cancer is characterized by such a genetic instability that a 'mutagen sensitive' phenotype is not necessarily indicating a pre-existing susceptibility factor. In spite of such criticisms, and of the aspecificity of mutagen sensitivity tests, the burden of investigations suggesting a greater sensitivity of some subjects to DNA damaging agents is impressive. Furthermore, the credibility of the observation is enhanced by the fact that in some investigations also healthy relatives of cancer patients - belonging to high-risk families - showed increased 'mutagen sensitivity' or impaired DNA repair.

In addition to such studies, several investigations on DNA adducts suggest that cancer patients have a higher level of adducts after adjustment for relevant exposures. For example, in a study on bladder cancer we have found that, after adjustment for smoking and occupational exposures, the level of WBC-DNA adducts was the variable that had the strongest association with the case vs. controls status ${ }^{45}$. Similar observations have been made by others ${ }^{46}$.

The study of interactions between this kind of increased susceptibility to DNA damage and dietary exposures is still very immature. However, in a recent investigation Palli et al. have shown that a high consumption of fruit and vegetables can modulate the concentration of WBC-DNA (bulky) adducts in healthy individuals ${ }^{47}$, consistently with a case-control study on bladder cancer ${ }^{48}$.

\section{Role of cumulative exposures}

Epidemiologic studies have shown that in many instances duration of exposure is more important than the daily dose in increasing the risk of cancer. The paradigm for this general relationship is represented by smoking and lung cancer, but also experimental evidence has been produced. In the case of smoking, the incidence of lung cancer increased with the 4th power of duration and the 2nd power of daily dose in one study ${ }^{49}$. Other investigations did not find such a strong discrepancy between dose and duration, but the latter was nevertheless more relevant. Duration is mainly due to age at start; classical epidemiological studies have shown a very strong association between earlier age at start of smoking and the risk of lung cancer. In animals, repeated doses induced tumours more frequently than the same total amount administered as a single dose $\mathrm{e}^{50-52}$. The latter observation is at odds with the general mechanisms of toxicity, according to which heavy exposure in a single administration has more devastating effects than repeated small doses (there are, however, some notable exceptions: not all carcinogens follow the rule suggested above).

In the light of such observations, a possible interpretation of the higher levels of adducts among cancer cases compared to controls is the concept of 'cumulative unrepaired DNA damage' (CUDD). What causes cancer - roughly speaking - would be the total burden of genotoxic chemicals that bind to DNA overcoming the repair processes. Such a burden may be higher because DNA repair is impaired (for genetic or acquired reasons) or because repeated exposures to the same agent occur. The intake of certain foods or nutrients can modulate the interaction between carcinogenc exposures and DNA damage, as the investigations on DNA bulky adducts, mentioned above, suggest ${ }^{47,48}$.

\section{Practical consequences for genetic testing}

If the premises are correct, important practical consequences follow.

First, the contribution of genetic screening of populations is doomed to be rather limited. Genetic screening is sensible if at least two conditions are met: that the identification of a mutation is followed by effective preventive/therapeutic measures, that prolong survival and improve the quality of life; that the population examined shows a high prevalence of mutants as to achieve a high predictive value of the screening test. If the prevalence of the mutation in the population is low even in the case we have effective preventive/therapeutic means - a screening strategy is unrealistic, since we have to screen many thousands to find one true positive plus (usually) a large number of false positives. So, rare mutations can be reasonably sought in families, not in the general population.

Conversely, if the mutation is frequent (a polymorphism) its penetrance is likely to be very low and its effects to depend on interaction with external exposures. In such a case, even if the predictive value of the test is high (i.e. there are relatively few false positive results), the success of screening is low: how can we deal effectively with 50\% of the population (those with the GSTM1 null genotype) who have a 30-40\% excess risk of lung cancer? The best action is to advice them not to expose themselves to carcinogens, e.g. not to smoke, but such advice should be obviously extended to the remaining 50\% of the population. Similar considerations can be made for folate deficiency and MTHRF polymorphisms, or dietary exposure to heterocyclic arylamines and NAT2.

Another even better reason why genetic screening for common polymorphisms is not feasible is that multiple polymorphisms (tens or even hundreds) are involved in modulating the risk of cancer. Therefore, it makes little sense to identify a GSTM1 null individual if the same person is at low risk for other metabolizing enzymes. It is rather obvious that for polymorphic conditions that 
Table 2 Screening strategies: Number Needed to Treat (NNT)

\begin{tabular}{lcc}
\hline & \multicolumn{2}{c}{ Genotype } \\
\cline { 2 - 3 } & Low penetrance & High penetrance \\
\hline Risk of cancer without screening (U) & 0.014 & 0.37 \\
Risk reduction due to screening $(\mathrm{U}-\mathrm{T}) / \mathrm{U}$ & $58 \%$ & $58 \%$ \\
Risk of cancer in the screenees $(\mathrm{T})$ & 0.006 & 0.155 \\
Absolute reduction of risk $(\mathrm{U}-\mathrm{T})$ & 0.008 & 0.215 \\
NNT to prevent one cancer 1/(U-T) & $1 / 0.008=125$ & $1 / 0.215=4.5$ \\
\hline
\end{tabular}

interact with external exposures the only reasonable approach is avoidance of exposure.

The preceding considerations will be clearer if we provide a quantitative example, based on the concept of NNT (Number Needed to Treat) (Table 2). Let us imagine we have two different genetic traits, one with low penetrance $(1.4 \%$ of cumulative lifetime risk in the carriers), and one with high penetrance (37\% cumulative risk). Let us suppose that screening allows us to reduce the risk of cancer by $58 \%$ in both cases. This means that the absolute risk goes down to 6 per thousand in category $\mathrm{A}$ and to $15.5 \%$ in category $\mathrm{B}$, with an absolute reduction of 8 per thousand and $21.5 \%$ respectively. The Number Needed to Treat is the inverse of such figures, i.e. 125 in category A and 4.5 in category B. This means that we have to identify and treat 125 subjects to prevent one death in category A, while it is sufficient to treat 4.5 individuals in category B to achieve the same result. The Number Needed to Screen is given by the NNT divided by the prevalence of the mutation/polymorphism.

In conclusion, what practical strategies can be proposed? If we accept that genetic screening should be limited to high-risk families, and that, apart from these, the risk of cancer depends on the total cumulative unrepaired DNA damage (CUDD), then we must admit that avoidance of exposure is the only realistic approach, even for low levels of exposure. Low levels of exposures have two properties that make them quite relevant to the population cancer risk: they are frequent or even ubiquitous (e.g. dietary components, air or water pollution) and they are prolonged rather than limited in time. The average person in Western societies is exposed to low-level genotoxic pollutants for all her life. Such lowlevel exposure starts at a very young age and induces cumulative DNA damage which, if unrepaired, will be able to increase the cancer risk. Although a great deal of controversies have arisen about 'thresholds' for carcinogens, little attention has been paid to long-lasting exposures.

The relatively sparse considerations above suggest that there is a need for specific and well-designed guidelines for the interpretation of data on genetic susceptibility and their practical implications. Concerning dietary habits, there is no evidence that screening for genetic susceptibility involved in the relationships between diet and disease (e.g. MTHFR or NAT2) might bring any Public
Health advantage. On the contrary, there is some evidence that dietary exposures (fruit and vegetables) can exert a modulating effect over the interaction between carcinogenic exposures, genetic susceptibility and DNA damage.

\section{References}

1 Vogelstein B, Kinzler KW. The genetic basis of buman cancer. McGraw-Hill, New York, 1998.

2 Shen MR, Jones IM, Mohrenweiser H. Nonconservative amino acid substitution variants exist at polymorphic frequency in DNA repair genes in healthy humans. Cancer Res. 1998; 58: 604-608.

3 Bailey LB, Gregory JF $3^{\text {rd }}$. Polymorphisms of methylenetetrahydrofolate reductase and other enzymes: metabolic significance, risks and impact on folate requirement. $J$. Nutr. 1999; 129(5): 919-922.

4 Zhang S, Hunter DJ, Forman MR, Rosner BA, Speizer FE, Colditz GA, Manson JE, Hankinson SE, Willett WC. Dietary carotenoids and vitamins $\mathrm{A}, \mathrm{C}$, and $\mathrm{E}$ and risk of breast cancer. J. Natl. Cancer Inst. 1999 Mar 17; 91(6): 547-56.

5 Chen J, Giovannucci EL, Hunter DJ. MTHFR polymorphism, methyl-replete diets and the risk of colorectal carcinoma and adenoma among U.S. men and women: an example of gene-environment interactions in colorectal tumorigenesis. J. Nutr. 1999; 129(2S Suppl): 560S-564S.

6 Chen J, Giovannucci E, Hankinson SE, Ma J, Willett WC, Spiegelman D, Kelsey KT, Hunter DJ. A prospective study of methylenetetrahydrofolate reductase and methionine synthase gene polymorphisms, and risk of colorectal adenoma. Carcinogenesis 1998; 19(12): 2129-2132.

7 Morita H, Kurihara H, Tsubaki S, Sugiyama T, Hamada C, Kurihara Y, Shindo T, Oh-hashi Y, Kitamura K, Yazaki Y. Methylenetetrahydrofolate reductase gene polymorphism and ischemic stroke in Japanese. Arterioscler Thromb. Vasc. Biol. 1998; 18(9): 1465-1469.

8 Girelli D, Friso S, Trabetti E, Olivieri O, Russo C, Pessotto R, Faccini G, Pignatti PF, Mazzucco A, Corrocher R:. Methylenetetrahydrofolate reductase C677T mutation, plasma homocysteine, and folate in subjects from northern Italy with or without angiographically documented severe coronary atherosclerotic disease: evidence for an important geneticenvironmental interaction. Blood 1998; 91(11): 4158-4163.

9 Ma J, Stampfer MJ, Hennekens CH, Frosst P, Selhub J, Horsford J, Malinow MR, Willett WC, Rozen R: Methylenetetrahydrofolate reductase polymorphism, plasma folate, homocysteine, and risk of myocardial infarction in US physicians. Circulation 1996; 94(10): 2410-2416.

10 Roberts-Thomson IC, Ryan P, Khoo KK, Hart WJ, McMichael AJ, Butler RN. Diet, acetylator phenotype and risk of colorectal neoplasia. The Lancet 1996; 347(9012): 13721374 .

11 Vineis P, McMichael AJ. Interplay between heterocyclic amines in cooked meat and metabolic phenotype in the 
etiology of colon cancer. Cancer Causes Control 1996; 7: 479-486.

12 Pero RW, Miller DG, Lipkin M, Malkowitz M, Gupta S, Winawer SJ, Enker W, Good R. Reduced capacity for DNA repair synthesis in patients with or genetically predisposed to colorectal cancer. JNCI 1993; 70: 867-875.

13 Pero RW, Ritchie M, Winawer SJ, Markowitz MM, Miller DGF. Unscheduled DNA synthesis in mononuclear leukocytes from patients with colorectal polyps. Cancer Res. 1995; 45: 3388-3391.

14 Kiecolt-Glaser JK, Stephens RE, Lipetz PD, Speciher CE, Glaser R. Distress and DNA repair in human lymphocytes. $J$. Behavioral Medicine 1985; 8: 311-320.

15 Kovacs E, Stucki D, Weber W, Muller H. Impaired DNA-repair synthesis in lymphocytes of breast cancer patients. Eur. J. Cancer Clin. Oncol. 1986; 22: 863-869.

16 Roth M, Muller H, Boyle JM. Immunochemical determination of an initial step in thymine dimer excision repair in xeroderma pigmentosum variant fibroblasts and biopsy material from the normal population and patients with basal cell carcinoma and melanoma. Carcinogenesis 1987; 8 : 1301-1307.

17 Kovacs E, Almendral A. Reduced DNA repair synthesis in healthy women having first degree relatives with breast cancer. Eur. J. Cancer. Clin. Oncol. 1987; 23: 1051-1057.

18 Kovacs E, Langemann $H$. Defective DNA repair in a large family having a high occurrence of cancer. Oncology 1988; 45: 444-447.

19 Markowitz MM, Johnson DB, Pero RW, Winawer SJ, Miller DG. Effects of cumene hydroperoxide on adenosine diphosphate ribosyl transferase in mononuclear leukocytes of patients with adenomatous polyps in the colon. Carcinogenesis 1998; 9: 349-355.

20 Pero RW, Johnson DB, Miller DG, Zang E, Markowitz M, Doyle GA, Lund-Pero M, Salford L, Sordillo P, Raskin N, Beattie EJ. Adenosine diphosphate ribosyl transferase responses to a standardized dose of hydrogen peroxide in the mononuclear leukocytes of patients with a diagnosis of cancer. Carcinogenesis 1989; 10: 1657-1664.

21 Spitz MR, Fueger JJ, Beddingfield NA, Annegers JF, Hsu TC, Newell GR, Schantz SS. Chromosome sensitivity to Bleomycin-induced mutagenesis, an independent factor for upper aerodigestive tract cancers. Cancer Res. 1989; 49: 4626-4628.

22 Pero RW, Johnson DB, Markowitz MM, Doyle G, Lund-Pero M, Seidegard J, Halper M, Miller DG. DNA repair synthesis in individuals with and without a family history of cancer. Carcinogenesis 1989; 10: 693-697.

23 Schantz SP, Spitz MR, Hsu TC. Mutagen sensitivity in patients with head and neck cancers: a biologic marker for risk of multiple primary malignancies. JNCI 1990; 82: 1773-1775.

24 Alcalay J, Freeman SE, Goldberg LH, Wolf JE. Excision repair of pyrimidine dimers induced by simulated solar radiation in the skin of patients with basal cell carcinoma. J. Invest. Dermatol. 1990; 95: 506-509.

25 Athas WF, Hedayati MA, Matanoski GM, Farmer ER, Grossman L. Development and field-test validation of an assay for DNA repair in circulating human lymphocytes. Cancer Res. 1991; 51: 5786-5793.

26 Kovacs E, Langemann H. Differences in the kinetics of DNA repair in cancer patients and healthy controls. Oncology 1991; 48: 312-316.

27 Spitz MR, Fueger JJ, Halabi S, Schantz SP, Sample D, Hsu TC. Mutagen sensitivity in upper digestive tract cancer: a casecontrol analysis. Cancer Epidemiol. Biomarkers Prev. 1993; 2: $329-333$.

28 Parshad R, Price FM, Pirollo KF, Chang EH, Sanford KK. Cytogenetic response to G2-Phase $\mathrm{X}$ irradiation in relation to DNA repair and radiosensitivity in a cancer prone family with Li-Fraumeni syndrome. Radiation Res. 1993; 136: 236-240.
29 Wei Q, Matanoski GM, Farmer ER, Hedayati MA, Grossman L. DNA repair and aging in basal cell carcinoma: a molecular epidemiology study. PNAS 1993; 90: 1614-1618.

30 Spitz MR, Hoque A, Trizna Z, Schantz P, Amos CI, King TM, Bondy ML, Hong WK, Hsu TC. Mutagen sensitivity as a risk factor for second malignant tumors following malignancies of the upper aerodigestive tract. JNCI 1994; 86: $1681-1684$

31 Scott D, Spreadborough A, Levine E, Roberts SA. Genetic predisposition in breast cancer. Lancet 1994; 344: 1444.

32 Hall J, English DR, Artuso M, Armstrong BK, Winter M. DNA repair capacity as a risk factor for non-melanocytic skin cancer - a molecular epidemiological study. Int. J. Cancer 1994; 58: 179-184.

33 Spits AR, Hsu TC, Wu X, Fueger JJ, Amos CI, Roth JA. Mutagen sensitivity as a biological marker of lung cancer risk in African Americans. Cancer Epidemiol. Biomarkers Prev. 1995; 4: 99-103.

34 Wei G, Cheng L, Hong WK, Spitz MR. Reduced DNA repair in lung cancer patients. Cancer Res. 1996; 56: 4103-4107.

35 Li D, Wang M, Cheng L, Spitz MR, Hittelman WN, Wei Q. In vitro induction of benzo(a)pyrene diol epoxide-DNA adducts in peripheral lymphocytes as a susceptibility marker for human lung cancer. Cancer Res. 1996; 56 3638-3641.

36 Scott D, Spreadborough AR, Jones LA, Roberts SA, Moore CJ. Chromosomal radiosensitivity in G2-Phase lymphocytes as an indicator of cancer predisposition. Radiation Res. 1996; 145: 3-16.

37 Parshad R, Price FM, Bohr VA, Cowans KH, Zujewski JA, Sanford KK. Deficient DNA repair capacity, a predisposing factor in breast cancer. Br. J. Cancer 1994; 74: 1-5.

38 Schantz SP, Zhang ZF, Spitz MS, Sun M, Hsu TC. Genetic susceptibility to head and neck cancer: interaction between nutrition and mutagen sensitivity. The Laryngoscope 1997; 107: 765-781.

39 Hu JJ, Roush GC, Dubin N, Berwick M, Roses DF, Harris MN. Poly (ADP-ribose) polymerase in human breast cancer: a case-control study. Pharmacogenetics 1997; 7: 309-316.

40 Jaloszynski P, Kujawski M, Czub-Swierczek M, Markowska J, Szyfter K. Bleomycin-induced DNA damage and its removal in lymphocytes of breast cancer patients studied by comet assay. Mut. Res. 1997; 385: 223-233.

41 Patel RK, Trivedi AH, Arora DC, Bhatavdekar JM, Patel DD. DNA repair proficiency in breast cancer patients and their first-degree relatives. Int. J. Cancer 1997; 73: 20-24.

42 Spitz MR, Lippman SM, Jiang H, Lee JJ, Khuri F, Hsu TC, Trizna Z, Schantz SP, Benner S, Hong WK. Mutagen sensitivity as a predictor of tumor recurrence in patients with cancer of the upper aerodigestive tract. JNCI 1998; 90 $243-245$.

43 Moller P, Knodsen LE, Frentz G, Dybdahl M, Wallin H, Nexo BA. Seasonal variation of DNA damage and repair in patients with non-melanoma skin cancer and referents with and without psoriasis. Mutation. Res. 1998; 407: 25-34.

44 Rao NM, Pai SA, Shinde SR. Gosh SN Reduced DNA repair capacity in breast cancer patients and unaffected individuals from breast cancer families. Cancer Genet. Cyotogenet. 1998; 102: $65-73$.

45 Peluso M, Airoldi L, Armelle M, Martone T, Coda R, Malaveille C, Giacomelli G, Terrone C, Casetta G, Vineis P. White blood cell DNA adducts, smoking, and NAT2 and GSTM1 genotypes in bladder cancer: a case-control study. Cancer Epidemiol. Biomarkers Prev. 1998; 7: 341-346.

46 Perera FP. Molecular epidemiology: insights into cancer susceptibility, risk assessment, and prevention. JNCI 1996; 88: 496-509.

47 Palli D, Vineis P, Russo A, Berrino F, Krogh V, Masala G, Munnia A, Panico S, Taioli E, Tumino R, Garte S, Peluso M. Diet, metabolic polymorphisms and dna adducts: The 
epic-Italy cross-sectional study. Int. J. Cancer 2000; 87(3): 444-451.

48 Peluso M, Airoldi L, Magagnotti C, Fiorini L, Munnia A Hautefeuille A, Malaveille C, Vineis P. White blood cell DNA adducts and fruit and vegetable consumption in bladder cancer. Carcinogenesis 2000; 21(2): 183-187.

49 Doll R, Peto R. Cigarette smoking and bronchial carcinoma: dose and time relationships among regular smokers and lifelong non-smokers. J. Epidemiol. Comm. Health 1978; 32: 303-313.

50 Lee PN, O'Neill JA. The effect of both time and dose on tumor incidence rate in benzopyrene skin painting experiments. Br. J. Cancer 1971; 25: 759-770.

51 Lee PN, Rothwell K, Whitehead JK. Fractionation of mouse skin carcinogens in cigarette smoke condensate. $\mathrm{Br} . \mathrm{J}$. Cancer 1977; 35: 730-742.

52 Iversen $\mathrm{OH}$. The skin tumorigenic and carcinogenic effects of different doses, numbers of dose fractions and concentrations of 7,12-dimethylbenz[a]anthracene in acetone applied on hairless mouse epidermis. Possible implications for human carcinogenesis. Carcinogenesis 1991 Mar; 12(3): 493-502. 